\title{
IMPACTO DE INSETICIDAS SOBRE SPODOPTERA FRUGIPERDA (LEPIDOPTERA, NOCTUIDAE) E SEUS INIMIGOS NATURAIS EM MILHO SAFRINHA CULTIVADO EM CASSILÂNDIA E CHAPADÃO DO SUL, MS
}

\author{
L.C. Toscano ${ }^{1}$, G.C. Calado Filho ${ }^{1}$, A.M. Cardoso ${ }^{2}$, W.I. Maruyama ${ }^{1}$, G.V. Tomquelski ${ }^{3}$ \\ ${ }^{1}$ Universidade Estadual de Mato Grosso do Sul, Rod. MS 306, km 6,4, CEP 79540-000, Cassilândia, MS, Brasil. \\ E-mail: toscano@uems.br
}

\section{RESUMO}

Tendo em vista que a ocorrência de Spodoptera frugiperda pode prejudicar a produtividade do milho e que seu controle é basicamente feito com o uso de inseticidas químicos, é fundamental que o manejo desta praga seja aprimorado através do estudo de seletividade destes produtos frente à população dos agentes de controle biológico. Assim, foram avaliadas a ação do inseticida regulador do crescimento de insetos lufenurom (Match EC - 0,3 L/ ha ${ }^{-1}$ ) e do organofosforado clorpirifós (Clorpirifós Fersol 480 EC - 0,6 L/ ha-1), na supressão de populações da lagarta-do-cartucho e seu impacto sobre alguns de seus agentes de controle biológico em Cassilândia e Chapadão do Sul, MS. As avaliações foram realizadas semanalmente em 100 plantas que ficavam distribuídas em 10 pontos ao acaso/tratamento, considerando-se as seguintes variáveis: oviposição, cartuchos atacados e ocorrência de agentes de controle biológico. A aplicação dos produtos não interferiu de maneira significativa no número de posturas encontradas nos tratamentos; o inseticida lufenurom foi o que apresentou maior eficiência no controle da lagarta-do-cartucho e teve menor efeito deletério sobre as populações dos inimigos naturais em relação ao clorpirifós. Além das aranhas e do predador Doru luteipes, as espécies de parasitoides de lagarta encontradas foram Chelonus sp., Campoletis sp. e Euplectrus sp.

PALAVRAS-CHAVE: Zea mays, lagarta-do-cartucho, controle químico, parasitoides, predadores.

\section{ABSTRACT}

IMPACTOFINSECTICIDESON SPODOPTERA FRUGIPERDA(LEPIDOPTERA, NOCTUIDAE) ANDITSNATURALENEMIESONOFF-SEASONMAIZEINCASSILÂNDIA ANDCHAPADÃODO SUL, STATE OF MATO GROSSO DOSUL, BRAZIL. Due to the fact that the occurrence of Spodoptera frugiperda can harm maize yields and is controlled basically through the use of chemical insecticides, it is crucial to improve the management of this pest by studying the insecticides' selectivity regarding the population of biological control agents. Therefore, the insecticide with insect growth regulating properties lufenuron (Match EC - $0.3 \mathrm{~L} / \mathrm{ha}^{-1}$ ) and the organophosphate chlorpyrifos (Clorpirifós Fersol $\left.480 \mathrm{EC}-0.6 \mathrm{~L} / \mathrm{ha}^{-1}\right)$, were analyzed regarding the control of fall armyworm populations and their impact on biological control agents in Cassilândia and Chapadão do Sul, State of Mato Grosso do Sul, Brazil. The analyses were performed weekly considering 100 plants which were distributed in 10 spots at random/treatment, regarding the variables: oviposition, attacked whorls and occurrence of biological control agents. The use of the products did not significantly affect the number of observed ovipositions in the treatments; the insecticide lufenuron showed higher efficiency on the control of fall armyworm and lower deleterious effects on the populations of natural enemies when compared to chlorpyrifos. Besides spiders and the predator Doru luteipes, the observed parasitoid species of the caterpillar were Chelonus sp., Campoletis sp. and Euplectrus sp.

KEY WORDS: Zea mays, fall armyworm, chemical control, parasitoids, predators.

\section{INTRODUÇÃO}

Considerada uma das culturas mais importantes para a agricultura brasileira, o cultivo do milho,
Zea mays L., é feito principalmente em duas épocas distintas do ano, verão (safra) e outono (safrinha). De acordo com ConAB (2011), a área cultivada com grãos na safra 2009/10 totalizou 47,39 milhões de

${ }^{2}$ Instituto Federal de Educação, Ciência e Tecnologia de São Paulo, Matão, SP, Brasil.

${ }^{3}$ Fundação de Apoio à Pesquisa Agropecuária de Chapadão, Chapadão do Sul, MS, Brasil. 
hectares e o milho representou uma área cultivada de 12,57 milhões de hectares, com produção de 55,97 milhões de toneladas e produtividade média nacional de $4.316 \mathrm{~kg} / \mathrm{ha}$, já a área cultivada com a safrinha foi de 5,24 milhões de hectares e produção de 21,89 milhões.

Independente da época de cultivo, diversos são os fatores responsáveis pela baixa produtividade, porém, um dos considerados mais limitantes é a ocorrência da lagarta-do-cartucho, Spodoptera frugiperda(J.E.Smith, 1797) (Lepidoptera: Noctuidae), considerada praga-chave da cultura do milho. Particularmente, durante o cultivo da safrinha, esta praga torna-se ainda mais impactante para a produção, pois as condições climáticas favoráveis e a permanência de plantas de milho nas áreas durante praticamenteo ano todo contribuem com o surgimento de gerações consecutivas (CRUZ, 1993).

Logo após a emergência das plantas de milho, com o surgimento das primeiras folhas, é possível observar as posturas efetuadas pelos adultos deste inseto. Durante esta fase inicial de desenvolvimento das plantas, as lagartas de primeiro ínstar iniciam sua alimentação, porém, elas apenas raspam a epiderme e o parênquima foliar, originando um sintoma conhecido como "folha raspada". Conforme se desenvolvem, as lagartas tornam-se mais agressivas e já começam a fazer furos maiores nas folhas, quando podem destruir totalmente as plantas mais novas. Assim, em função das injúrias que esta praga provoca nas plantas, reduções significativas dos índices de produtividade das lavouras vêm sendo observadas a cada ano durante o cultivo do milho (FARINELLI; Fornasieri FilHo, 2006; FERnANDES; CaRneIRO, 2006; Figueiredo et al., 2006; Araújo et al., 2011; Michelotto et al., 2011) e, caso medidas de controle não sejam adotadas, os índices de produtividade podem ser totalmente comprometidos, podendo chegar à perdas de até $100 \%$.

Tradicionalmente, o manejo desta praga é realizado através de produtos químicos cuja escolha nem sempre leva em consideração o grau de seletividade aos agentes de controle biológico. Conforme relatado por BRUNNER (1994), a escolha de produtos com amplo espectro de ação pode limitar a integração do controle químico com o biológico no manejo de pragas agrícolas. Entretanto, progressos significativos têm sido feitos com o desenvolvimento de produtos seletivos, aumentando significativamente as possibilidades da integração de controle biológico e inseticidas químicos (CROFT, 1990; Dutcher, 1993). Conforme demonstrado por Degrande (1998) e BACCI et al. (2001), o emprego de inseticidas seletivos contribui com a preservação das espécies benéficas nos agroecossistemas onde estes produtos são empregados.

Ainda neste contexto, os produtos reguladores de crescimento dos insetos, como aqueles à base de lufenurom, mostram-se uma boa opção para utilização em programas de manejo integrado de pragas, visando a seletividade apresentada aos inimigos naturais, como citado por Pratissoli et al. (2004) para o parasitoide Trichogramma pretiosum. Os resultados indicaram alta seletividade em todos os testes realizados, principalmente na dosagem recomendada do princípio ativo para a cultura do milho $\left(0,3 \mathrm{~L} / \mathrm{ha}^{-1}\right)$.

Assim, os objetivos deste estudo foram de verificar a dinâmica populacional de $S$. frugiperda e de alguns de seus inimigos naturais, bem como avaliar o impacto do controle químico na população destes insetos, durante o cultivo de milho safrinha nos municípios de Cassilândia e Chapadão do Sul, MS.

\section{MATERIAL E MÉTODOS}

Foram instaladas duas áreas experimentais localizadas em municípios distintos da região Nordeste de Mato Grosso do Sul:

Ensaio em Cassilândia, MS: foi instalado na Unidade Universitária de Cassilândia da Universidade Estadual de Mato Grosso do Sul (UEMS) $\left(19^{\circ}\right.$ $05^{\prime}$ latitude Sul; $51^{\circ} 56^{\prime}$ longitude Oeste; altitude de $471 \mathrm{~m})$. A semeadura da variedade BM 2202 foi realizada em 19/3/2008 (0,45 m entre linhas e média de 5 plantas $/ \mathrm{m}$ ), totalizando área de $6.000 \mathrm{~m}^{2}$ que foi posteriormente dividida em 3 Campos de 2.000 $\mathrm{m}^{2}$ cada um (denominados de Campo I, II e III). A adubação de plantio (300 kg/ ha ${ }^{-1}$ de 08-20-20 + micro nutrientes) foi realizada de acordo com os resultados da análise de solo; a aplicação de $80 \mathrm{~kg} / \mathrm{ha}^{-1} \mathrm{de} \mathrm{N} \mathrm{em}$ cobertura foi dividida em duas aplicações.

Ensaio em Chapadão do Sul, MS: foi conduzido em área experimental da Fundação de Apoio à Pesquisa de Chapadão do Sul - Fundação Chapadão (18 $47^{\prime} 39^{\prime \prime}$ latitude Sul; $52^{\circ} 37^{\prime} 22^{\prime \prime}$ longitude Oeste; altitude de $810 \mathrm{~m}$ ). A semeadura da variedade AG 7000 foi realizada em 12/3/2008 (0,45 m entre linhas e média de 5 plantas / m), ocupando uma área de 600 $\mathrm{m}^{2}$ que foi, posteriormente, dividida em 3 Campos de $200 \mathrm{~m}^{2}$ cada um (denominados de Campo I, II e III). A adubação de plantio foi realizada de acordo com os resultados da análise de solo, utilizando-se $400 \mathrm{~kg} /$ ha $^{-1}$ de 07-18-09 (mais micronutrientes); para cobertura, foram utilizados $200 \mathrm{~kg} / \mathrm{ha}^{-1}$ de Ureia Kimcoat divididos em duas aplicações.

Avaliações e distribuição dos tratamentos: em cada Campo foram separados 10 pontos ao acaso com 10 plantas seguidas e ao acaso/campo (repetições), totalizando 100 plantas. Em cada uma destas áreas foram sendo realizadas avaliações semanais através de visualização direta (não destrutiva) observandose o sintoma de "folha raspada" ocasionados pelas lagartas; durante dois momentos estes sintomas 
atingiram $20 \%$ das plantase, baseando-se em CRUz et al. (1996), foram aplicados os seguintes tratamentos: 1) Testemunha, 2) Clorpirifós Fersol 480 EC (clorpirifós, organofosforado) $\left(0,6 \mathrm{~L} / \mathrm{ha}^{-1}\right)$ e 3) Match EC (lufenurom do grupo das Benzoilureias (0,3 L/ ha $\left.^{-1}\right)$, distribuídos respectivamente nos Campos I, II e III nas duas áreas experimentais. As aplicações foram realizadas com auxílio de pulverizador costal pressurizado $\left(\mathrm{CO}_{2}\right)$, com barra de pulverização de 3 metros, operando com pressão constante de 40 PSI, com calda de $200 \mathrm{~L} / \mathrm{ha}^{-1}$, utilizando pontas tipoleque XR-11002 com aplicação diretamente no cartucho.

As avaliações de ocorrência de lagartas após a aplicação foram feitas quinzenalmente através da coleta do cartucho de 100 plantas ao acaso/ tratamento; estes cartuchos foram levados para o laboratório e, após abertos, foi observada a ocorrência de lagartas e elas foram diferenciadas por tamanho, sendo consideradas pequenas $(<0,5 \mathrm{~cm})$, médias $(0,5-2,5 \mathrm{~cm})$ e grandes $(>2,5 \mathrm{~cm})$; posteriormente, estas lagartas foram acondicionadas em placas de Petri forradas com papel-filtro umedecido com água destilada para observar a emergência de parasitpoides ou de adultos de S. frugiperda. Durante este período, as lagartas foram alimentadas com folhas frescas de plantas de milho (sem tratamento e substituídas diariamente) coletadas no campo I (Testemunha).

As avaliações para os ovos foram realizadas semanalmente, sendo uma apenas visual e outra destrutiva simultaneamente à avaliação para as lagartas, considerando-se o número de posturas nos diferentes campos. No caso da avaliação destrutiva, quando foi observada a ocorrência de posturas da praga, essas massas de ovos foram recolhidas e acondicionadas como descrito anteriormente para lagartas a fim de se observar emergência de parasitoides.

Os parasitoides que emergiram dos ovos e/ou das lagartas foram conservados em álcool $70 \%$ e posteriormente identificados pela Dra. Angélica Maria Penteado Martins Dias, da Universidade Federal de São Carlos (UFSCar).

As avaliações e amostras foram analisadas para aferir do impacto das aplicações de inseticidas químicos sobre a população da praga e seus inimigos naturais. As médias do número de cartuchos atacados, das posturas e da ocorrência dos principais inimigos naturais foram comparadas pelo teste de Tukey a $5 \%$ de probabilidade utilizando-se e o programa estatístico SISVAR (FERREIRA, 2003).

\section{RESULTADOS E DISCUSSÃO}

Ensaio em Cassilândia, MS: a densidade populacional de lagartas (Fig. 1) mostra maior redução após as aplicações de lufenurom (36 e 29 insetos em relação à $1^{a}$ e $2^{a}$ aplicação, respectivamente), enquanto que o clorpirifós apresentou 51 e 41 insetos. As avaliações realizadas na testemunha nesta mesma época mostram que, independente do tamanho das lagartas, a densidade populacional de insetos foi sempre crescente, atestando a eficiência dos inseticidas. Elevadas taxas de mortalidade de lagartas em função da aplicação de inseticidas reguladores do crescimento de insetos, particularmente o lufenurom, também foram obtidas no trabalho realizado por Gomez; Ávila (2001), atestando a eficiência do inseticida no controle desta praga.

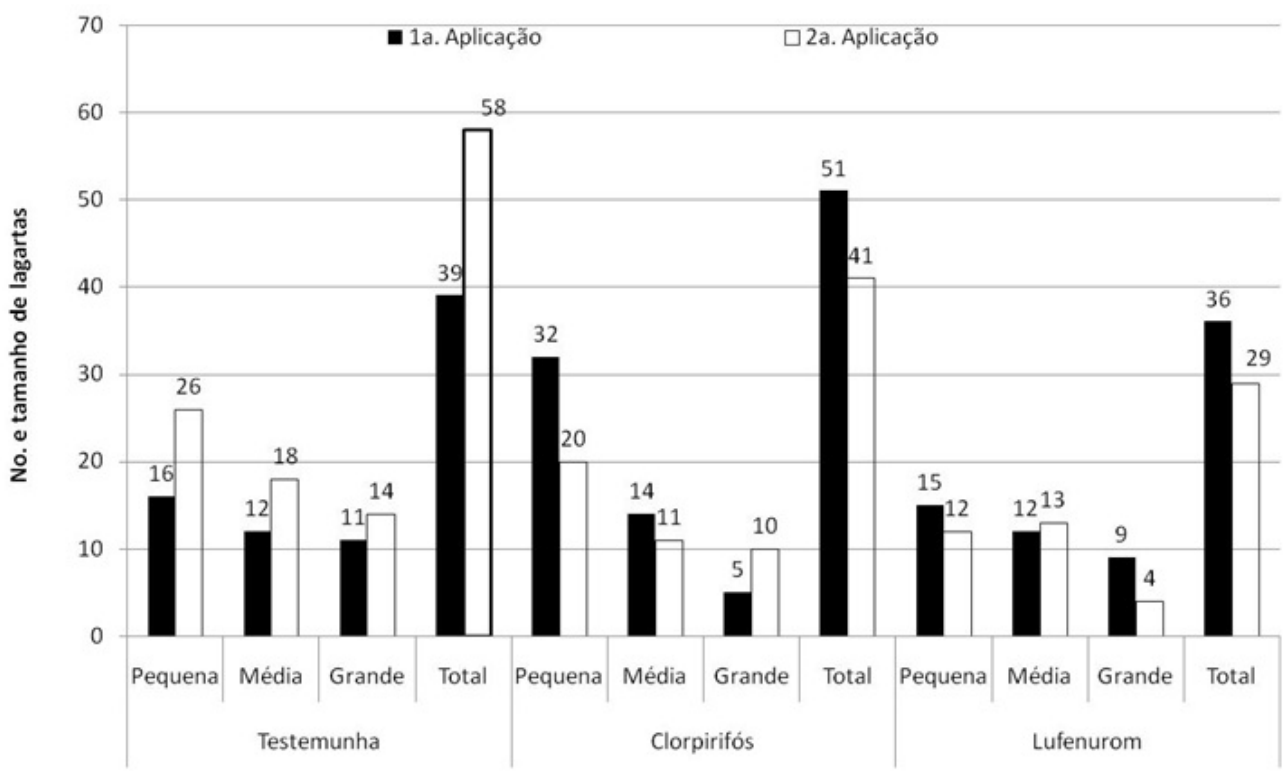

Fig. 1 - Número e tamanho de lagartas de Spodoptera frugiperda coletadas nos diferentes campos durante o cultivo do milho safrinha. Cassilândia, MS, 2008. 

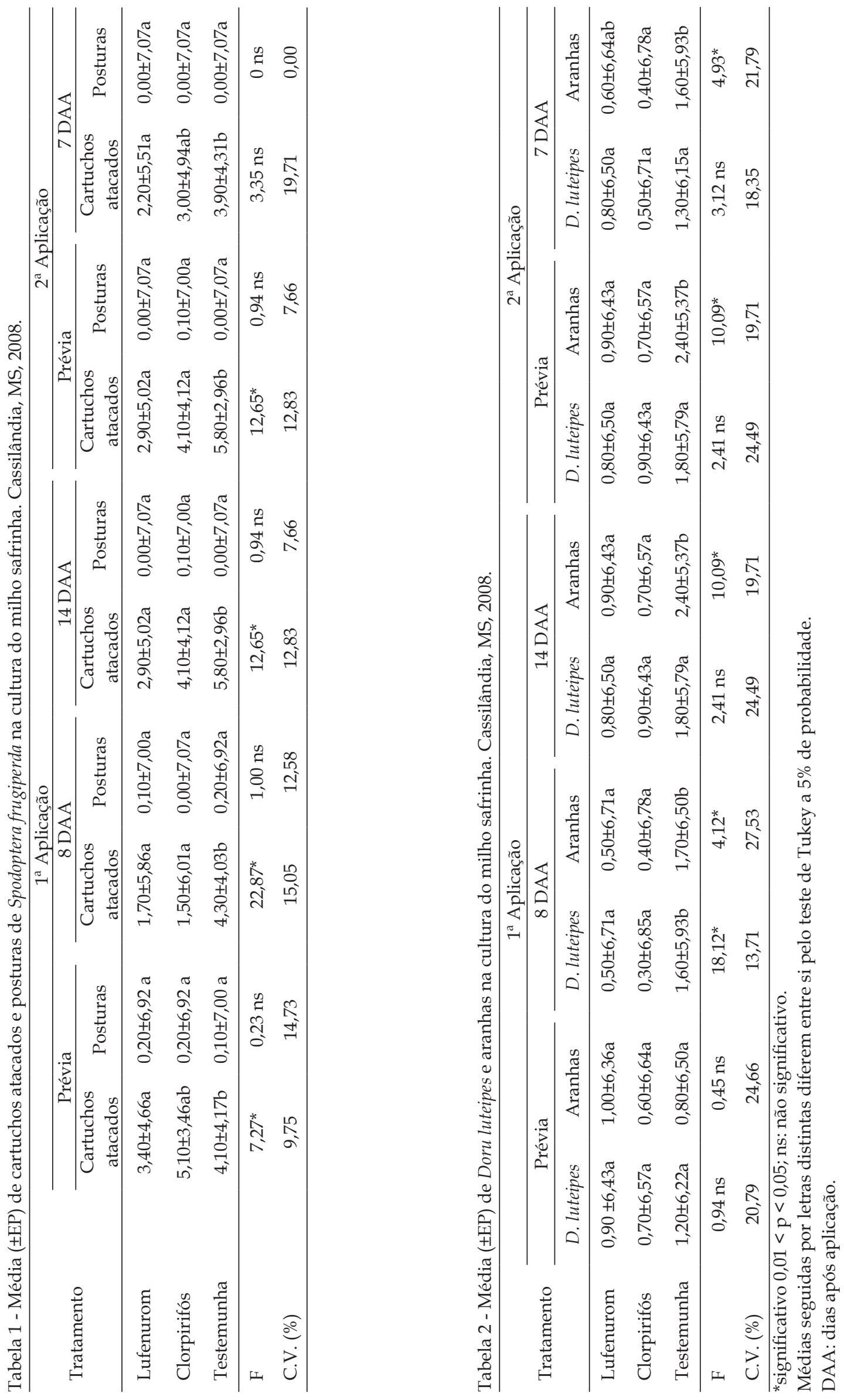

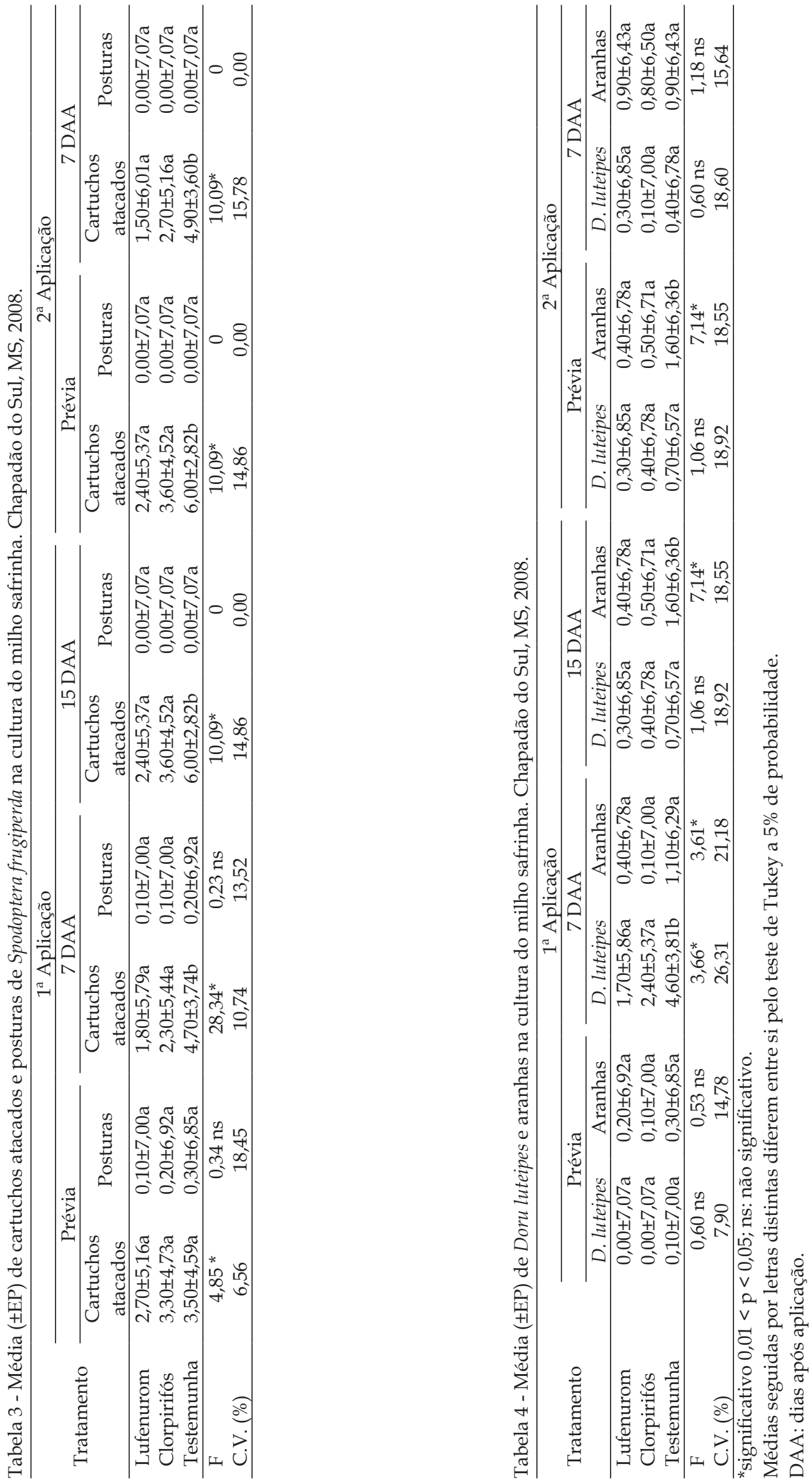


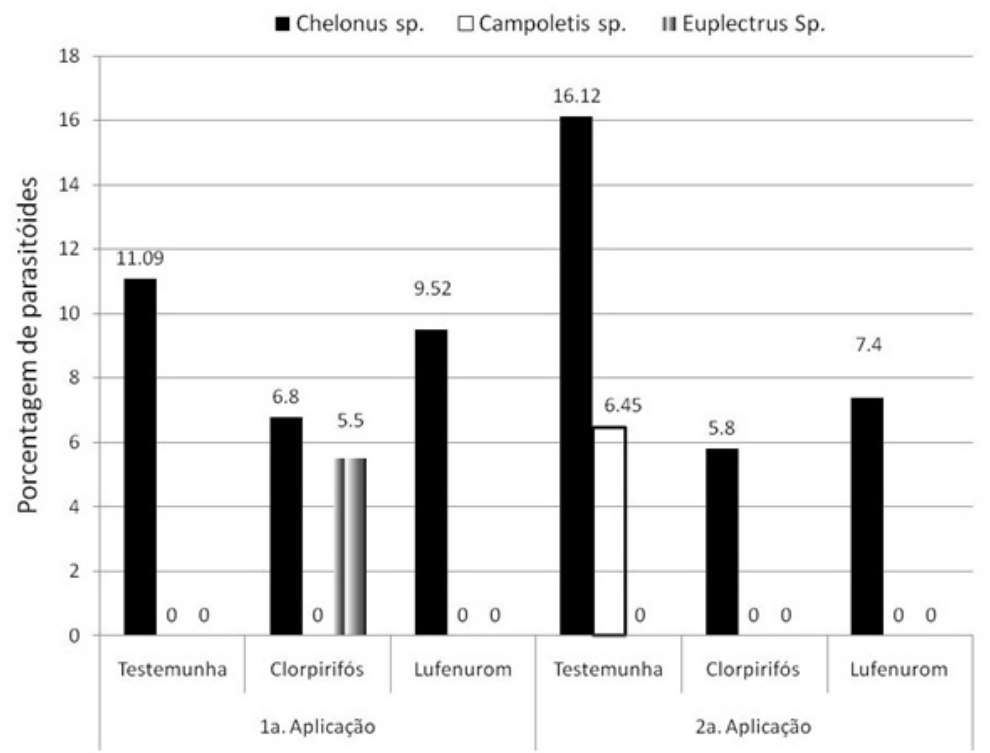

Fig. 2 - Porcentagem (\%) de parasitoides emergidos de lagartas de Spodoptera frugiperda coletadas no cultivo do milho safrinha. Cassilândia, MS, 2008.

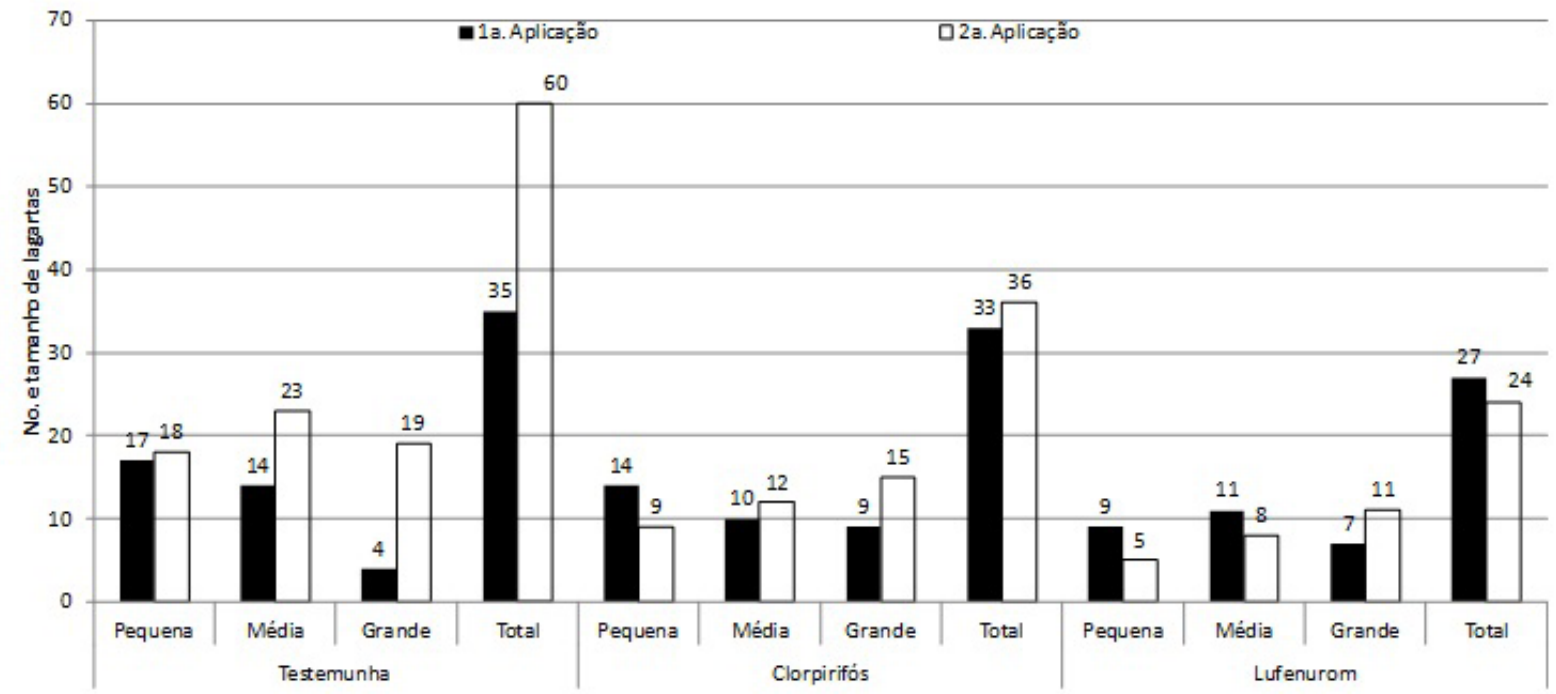

Fig. 3 - Número e tamanho de lagartas de Spodoptera frugiperda coletadas nos diferentes campos durante o cultivo do milho safrinha. Chapadão do Sul, MS, 2008.

A ocorrência de parasitoides em lagartas (Fig. 2) destaca-se que Chelonus sp. foi a espécie de maior abundância $(16,12 \%$ de parasitismo) em lagartas coletadas na testemunha; já nos Campos tratados com os inseticidas, os índices de parasitismo apresentaram variação de 5,8\% até o máximo de $9,52 \%$. Tais resultados indicam que o uso dos inseticidas contribuiu de certa forma para queda do parasitismo natural por este parasitoide, porém, entre os inseticidas utilizados no presente estudo, o mais seletivo foi o regulador do crescimento de insetos lufenurom, corroborando com PraTISSOLI et al. (2004). Estes autores comentam o efeito seletivo proporcionado pelo uso deste inseticida em testes realizados visando verificar a ação transovariana e efeito residual em ovos de $S$. frugiperda parasitados por T. pretiosum, outro parasitoide de ovos de ocorrência muito comum na cultura do milho. Também na testemunha foi observada a ocorrência de Campoletis sp. (com 6,45\% de parasitismo sobrelagartas). Euplectrus sp. ocorreu apenas no Campo tratado com o organofosforado, parasitando 5,5\% das lagartas coletadas. Segundo CRUZ (1995), estes agentes de controle biológico lideram o "ranking" da lista dos 
principais parasitoides de $S$. frugiperda assinalados na literatura mundial, portanto, é imprescindível a adoção de práticas que visem à conservação de suas populações a fim de contribuir com o manejo da lagarta-do-cartucho nas lavouras de milho.

Aos 8 e 14 dias após aplicação (DAA) ocorreram diferenças significativas para média de cartuchos injuriados entre os inseticidas aplicados ea testemunha, embora o mesmo não ocorreu entre os inseticidas (Tabela 1). Aos 7DAA, houve diferenciação somente entre o inseticida regulador docrescimento deinsetos e a testemunha, porém, não ocorreu diferença significativa entre os produtos. Em todas as avaliações, percebe-se que não houve diferença significativa para a média de posturas encontradas nos Campos experimentais, fato que pode estar relacionado ao período de incubação que é inferior ao intervalo de amostragem realizado no presente estudo, ou seja, 7 dias. Outro aspecto relacionado a esta distribuição uniforme de oviposição é que, segundo Cruz (1995), a nova geração de mariposas, antes de fazer sua postura, geralmente voa para longe da área de origem promovendo maior distribuição de massas de ovos sobre as plantas de milho.

Em todas as avaliações realizadas houve maior ocorrência de predadores no tratamento testemunha, sugerindo pouca seletividade dos inseticidas aos agentes de controle biológicos estudados (Tabela 2). Comparando-se os inseticidas pelo grupo químico, nota-se que apesar de não ter sido verificada, diferença significativa nos Campos em que se utilizou regulador de crescimento de insetos ocorreu maior preservação de Doru luteipes e das espécies de aranhas observadas, em relação aos Campos com organofosforado. O efeito seletivo aqui observado coincide com aquele obtido por GRÜTZMACHER et al. (2000) quanto à seletividade para outros agentes de controle biológico na cultura do milho.

Ensaio em Chapadão do Sul, MS: a eficiência de controle pode ser observada, pois, independente do tamanho das lagartas de $S$. frugiperda, os totais de indivíduos após aplicação foram maiores na testemunha e menores nos campos que receberam aplicação dos inseticidas (Fig. 3). Entre os inseticidas, a ocorrência destes insetos foi menor no campo que recebeu a aplicação de lufenurom (27 e 24 após a $1^{\mathrm{a}}$ e $2^{a}$ aplicação, respectivamente), em relação aos 33 e 36 no campo de clorpirifós. Os resultados de eficiência de controle aqui encontrados estão em consonância com os obtidos por Neri et al. (2005). Apesar de terem verificado a interação do uso deste inseticida com doses de silício para o manejo desta praga, estes autores também observaram eficiência de controle proveniente da aplicação isolada do lufenurom.

Sobre a ocorrência de inimigos naturais (Fig. 4), verifica-se que a maior ocorrência de Chelonus sp. foi no Campo onde as plantas não receberam aplicação dos inseticidas (Testemunha). Além disto, nesta mesma área, observa-se maior diversidade de agentes de controle biológico devido à ocorrência de Campoletis sp. Independente da espécie de parasitoide, cabe ressaltar que o número de indivíduos provavelmente foi maior nestes Campos devido à toxicidade que os produtos podem ter apresentado aos adultos destes insetos nos demais Campos ou, ainda, associados à falta do hospedeiro.

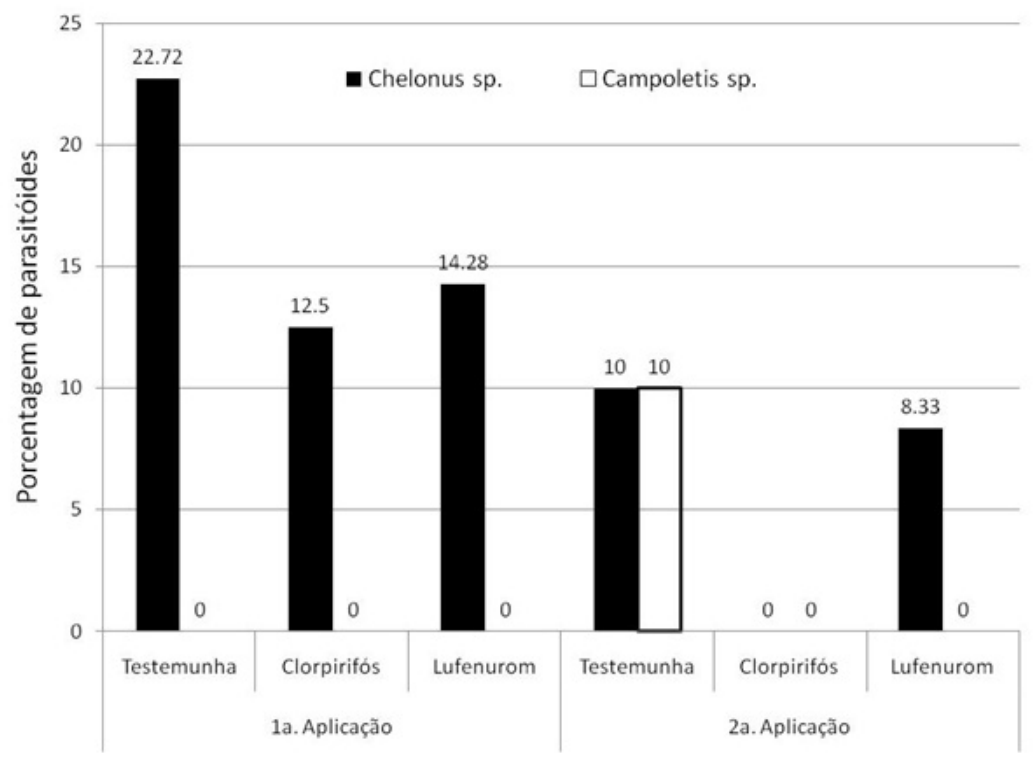

Fig. 4 - Porcentagem (\%) de parasitoides emergidos de lagartas de Spodoptera frugiperda coletadas no cultivo do milho safrinha. Chapadão do Sul, MS, 2008. 
Neste sentido, CRUZ (1995) comentou que a seletividade do inseticida químico é a chave do manejo de pragas e que o emprego destes produtos deve visar à redução da população dos insetos nocivos sem promover alterações significativas em outros componentes dos agroecossistemas e do ambiente de maneira geral. Campoletis sp. foi a espécie de parasitoideque ocorreu em porcentagem bem menor, corroborando com VALICENTE; BARRETO (1999), que fizeram levantamento em regiões produtoras do Paraná e obtiveram resultados semelhantes durante seus levantamentos.

Após as aplicações, a média de cartuchos atacados (Tabela 3) indica que aos 7 e 15 DAA os Campos que receberam os tratamentos lufenurom e clorpirifós diferiram significativamente da testemunha, mas não entre si. Ainda, no tratamento com o produto regulador do crescimento de insetos, os níveis de injúria provocados pelas lagartas sempre permaneceram inferiores quando comparados com o organofosforado. Em relação às posturas, em nenhum momento foi observada diferença significativa entre os tratamentos utilizados.

A ocorrência de D. luteipes (Tabela 4) mostra que, na avaliação realizada aos 7 dias após a primeira aplicação (7 DAA), ocorreu diferença significativa entre os inseticidas químicos e a testemunha, porém, não havendo diferença significativa entre si. Já aos 15 DAA, a média de ocorrência deste predador não apresentou diferença significativa. Para as aranhas, os resultados indicam que não ocorreu diferença entre os tratamentos aos $7 \mathrm{DAA}$, porém, já aos $15 \mathrm{DAA}$, os controles químicos diferiram da testemunha. Após a segunda aplicação, não houve diferença estatística significativa entre os tratamentos para a ocorrência de nenhum dos artrópodes estudados. De maneira geral, houve tendência de maior conservação das populações destes predadores nos campos com a utilização do inseticida regulador do crescimento de insetos.

\section{CONCLUSÕES}

Nas condições locais de Cassilândia e Chapadão do Sul (MS), em cultivo de milho safrinha, o inseticida regulador docrescimento deinsetoslufenurom (Match EC - 0,3 L/ha- ${ }^{-1}$ foi mais eficiente para o controle da lagarta-do-cartuchoe, ainda, apresentou menosimpacto negativo sobre a população dos agentes de controle biológico quando comparado com o organofosforado clorpirifós (Clorpirifós Fersol 480 EC - 0,6 L/ha-1).

\section{AGRADECIMENTOS}

À Dra. Angélica Maria Penteado Martins Dias (Universidade Federal de São Carlos, UFSCar) pela identificação dos parasitoides; ao FUNDECT pelo apoio financeiro, T.O. 88/06.

\section{REFERÊNCIAS}

ARAÚJO, L.F. de; SILVA, A.G. da; CRUZ, I.; CARMO, E.L. do; HORVATH NETO, A.; GOULART, M.M.P.; RATTES, J.F. Flutuação populacional de Spodoptera frugiperda (J. E. Smith), Diatraea saccharalis (Fabricius) e Doru luteipes (Scudder) em milho convencional e transgênico Bt. Revista Brasileira de Milho e Sorgo, v.10, n.3, p.205-214, 2011.

BACCI, L.; PICANÇO, M.C.; GUSMÃO, M.R.; CRESPO, A.L.B.; PEREIRA, E.J.G. Seletividade de inseticidas a Brevicoryne brassicae (L.) (Hemiptera: Aphididae) e ao predador Doru luteipes (Scudder) (Dermaptera: Forficulidae). Neotropical Entomology, v.30, n.4, p.707-713, 2001.

BRUNNER, J.F. Integrated pest management in tree fruit crops. Food Reviews International, v.10, n.2, p.135157, 1994.

CONAB - Companhia Nacional de Abastecimento (Brasil). Acompanhamento de safra brasileira: grãos, Quinto levantamento, fevereiro 2011/Companhia Nacional de Abastecimento. Brasília: CONAB, 2011.39p.

CROFT, B.A. Arthropod biological control agents and pesticides. New York: Wiley \& Sons, 1990. 732p.

CRUZ, I. Recomendações técnicas para o cultivo do milho: principais pragas e seu controle. Brasília: EMBRAPA-SPI, 1993. 204p.

CRUZ, I. A lagarta-do-cartucho na cultura do milho. Sete Lagoas: Embrapa-CNPMS, 1995. 45p. (Circular técnica, 21).

CRUZ, I.; OLIVEIRA, L.J.; OLIVEIRA, A.C.; VASCONCELOS, C.A. Efeito do nível de saturação de alumínio em solo ácido sobre os danos de Spodoptera frugiperda (J.E. Smith) em milho. Anais da Sociedade Entomológica do Brasil, v.25, n.2, p.293-297, 1996.

DEGRANDE, P.E. Manejo integrado de pragas do algodoeiro. In: EMBRAPA. Centro de Pesquisas Agropecuária do Oeste (CPAO-Dourados, MS). Algodão: informações técnicas. Campina Grande: EMBRAPA-CNPA, 1998. p.154-191. (Circular Técnica, 7).

DUTCHER, J.D. Recent examples of conservation of Arthropod natural enemies in agriculture. In: LUMSDEN, R.D.; VAUGHN, J.L. (Org.). Pest management: biologically based technologies. Washington: American Chemical Society, 1993. p.101-108.

FARINELLI, R.; FORNASIERI FILHO, D. Avaliação de dano de Spodoptera frugiperda (J. E. Smith, 1797) (Lepidoptera: Noctuidae) em cultivares de milho. Cientifica, v.34, n.2, p.197-202, 2006. 
FERNANDES, O.A.; CARNEIRO, T.R. Controle biológico de Spodoptera frugiperda no Brasil. In: PINTO, A.S.; NAVA, D.E.; ROSSI, M.M.; MALERBO-SOUZA, D.T.

(Org.). Controle biológico de pragas na prática. Piracicaba: CP 2, 2006. p.75-82.

FERREIRA, D.F. Sisvar: versão 4.2. Lavras: UFLA, 2003.

FIGUEIREDO, M.L.C.; MARTINS-DIAS, A.M.P.; CRUZ, I. Relação entre a lagarta-do-cartucho e seus agentes de controle biológico natural na produção de milho. Pesquisa Agropecuária Brasileira, v.41, n.12, p.1693-1698, 2006.

GOMEZ, S.A.; ÁVILA, C.J. Controle químico da lagarta-do-cartucho, Spodoptera frugiperda (J. E. Smith, 1797), na cultura do trigo. Dourados: Embrapa Agropecuária Oeste, 2001. 18p. (Boletim de Pesquisa e Desenvolvimento).

GRÜTZMACHER, A.D.; MARTINS, J.F.S.; AZEVEDO, R.; GIOLO, F.P. Efeito de inseticidas e de tecnologias de aplicação no controle da lagarta-do-cartucho na cultura do milho no agroecossistema de várzea. In: REUNIÃO TÉCNICA ANUAL DO MILHO, 45., 2000, Pelotas, RS. Anais. Pelotas: EMBRAPA-CPACT, 2000. p.567-573.

MICHELOTTO, M.D.; FINOTO, E.L.; MARTINS, A.L.M.; DUARTE A.P. Interação entre transgênicos (Bt) e inseticidas no controle de pragas-chave em híbridos de milho-safrinha. Arquivos do Instituto Biológico, São
Paulo, v.78, n.1, p.71-79, 2011. Disponível em: <http:/ / www.biologico.sp.gov.br/docs/arq/v78_1/michelotto. pdf>. Acesso em: nov. 2010.

NERI, D.K.P.; MORAES, J.C.; GAVINO, M.A. Interação silício com inseticida regulador de crescimento no manejo da lagarta-do-cartucho Spodoptera frugiperda (J. E. Smith, 1797) (Lepidoptera: Noctuidae) em milho. Ciência e Agrotecnologia, v.29, n.6, p.1167-1174, 2005.

PRATISSOLI, D.; THULER, R.T.; PEREIRA, F.F.; REIS, E.F. dos; FERREIRA, A.T. Ação transovariana de lufenurom $(50 \mathrm{~g} / \mathrm{L})$ sobre adultos de Spodoptera frugiperda (J. E. Smith) (Lepidoptera: Noctuidae) e seu efeito sobre o parasitóide de ovos Trichogramma pretiosum Riley (Hymenoptera: Trichogrammatidae). Ciência e Agrotecnologia, v.28, n.1, p.9-14, 2004.

VALICENTE F.H.; BARRETO M.R. Levantamento de inimigos naturais da lagarta do cartucho do milho, Spodoptera frugiperda (J. E. Smith) (Lepidoptera: Noctuidae), na região de Cascavel, PR. Anais da Sociedade Entomológica do Brasil, v.28, n.2, p.333-337, 1999.

Recebido em $4 / 4 / 11$

Aceito em 15/5/12 